\title{
A POLÍTICA DE GETÚLIO VARGAS E AS ESCOLAS PRIMÁRIAS DE SANTA CATARINA (1930-1945)
}

\author{
Daniele Hungaro da Silva*
}

\begin{abstract}
Resumo
O presente artigo discorre sobre a política de Vargas e seu grupo, bem como o projeto nacionalista para as escolas de Santa Catarina entre os anos de 1930 e 1945. O objetivo é de travar um diálogo, resultante do esforço de compreender o projeto nacionalista de Vargas em suas particularidades, que possibilite o entendimento acerca do caráter autoritário que teve este projeto para as escolas primárias de Santa Catarina. Quanto à metodologia, buscar-se-á fazer um apanhado geral das reformas políticas e as políticas educacionais que tiveram como proponentes o próprio governo, o ministro da Educação Gustavo Capanema e os chefes do Estado de Santa Catarina. Entre as reformas, salienta-se que o objetivo foi de homogeneizar a cultura, desconsiderando as já existentes no Estado. Neste sentido, os estudos de Campos (2008),Dallabrida (2003)ponderam que o papel fundamental que a escola desempenhou naqueles projetos de governo era de fazer uso de um arsenal de ideias patrióticas, de inspiração até mesmo fascista ou fascistizante, para a construção de uma identidade brasileira considerada "pura". Parte-se da compreensão de que o período do governo de Getúlio Vargas foi marcado por um nacionalismo exacerbado, autoritário, que penetrou as instituições escolares catarinenses. Na perspectiva de transformar as crianças em adultos dóceis e obedientes, no campo simbólico, a produção de discursos nos vários setores daquela sociedade intentou formar a chamada "identidade nacional".
\end{abstract}

Palavras-chave: Política Nacionalista. Autoritarismo. Escolas Primárias de Santa Catarina.

*Mestra em Educação pela Universidade Federal de Santa Catarina (UFSC).E-mail: danihungaro@hotmail.com 


\section{Introdução}

Para que se faça compreensão do governo que se quer ilustrar, buscamos o significado do termo autoritarismo em Bobbio, Matteucci e Pasquino (1998, p. 95), que, nas caracterizações dos sistemas políticos, chamam de autoritários os regimes que privilegiam a autoridade governamental, ao concentrar o poder político em um órgão, colocando em posição secundária as instituições representativas, sendo "[...] o autoritarismo um dos conceitos que, tal como 'ditadura' e 'totalitarismo', surgiram e foram usados em contraposição à 'democracia', pretendendo-se acentuar num caso ou noutro parâmetros antidemocráticos [...]”.

Entre alguns elementos contextuais, evidenciamos que o Estado Novo (1937-1945) ocorreu na mesma onda de transformações da política ditatorial que atingiu o mundo. Neste contexto mais específico, o projeto político de Vargas esteve relacionado, em certos aspectos, ao fascismo europeu. Identificamos, neste período, traços na cultura brasileira que evidenciaram como autoritário e ditatorial o governo comandado por Getúlio Vargas e seu grupo de poder. Mesmo assim, temos presente que a afirmação de que o governo getulista foi um governo de característica fascista e fascistizante no campo educacional escolar assume um tom de debate histórico controverso.

Nessa perspectiva, a escola seria um espaço estratégico para difundir o ideário de nação que se pretendia para as primeiras décadas do século XX. Por isso, buscamos reunir argumentos de que, durante o governo de Getúlio Vargas, nas instituições escolares de Santa Catarina, infância e juventude estariam sendo pensadas como espaço para intervir como pedra de lapidação das virtudes que a modernidade exigia, necessárias para sua formação.

Entre os argumentos que eventualmente justifiquem tal afirmação, temos que à escola foi dado o papel de moldar e constituir o cidadão ordeiro, mesclado das identidades de brasileiro e de trabalhador, necessárias para o fortalecimento e 
1 As formulações de Lúcia Lippi Oliveira (1982) abriram espaço para o estudo das relações entre cultura e a política no aspecto doutrinário do regime de Getúlio Vargas. o desenvolvimento da indústria emergente daquele contexto. Portanto, para que haja compreensão desses aspectos, primeiramente, faz-se necessário entender a sua relação com o contexto de transformações sociais.

O Brasil do século XX caracterizou-se por mudanças marcadas pelo fim do trabalho escravo, pelas transformações políticas após a implementação da República, pelas modificações econômicas com o início dos processos de industrialização, em especial o desenvolvimento do transporte ferroviário e da navegação a vapor, bem como pelas alterações sociais com as formas de transmigração humana nos diferentes espaços geográficos.

Nesse âmbito, situa-se a imigração de contingentes da população europeia para regiões brasileiras. O governo buscava encontrar novas formas de trabalho para aqueles trabalhadores não mais escravizados e para os imigrantes europeus que vinham preenchendo cada vez mais o espaço territorial do Brasil. E ambos os casos eram vistos como solução para a questão de mão de obra.

Após a Revolução de 1930, os alicerces do Regime Republicano e suas aspirações teriam sido abalados. Almir Andrade ${ }^{1}$, em entrevista à Lúcia Lippi Oliveira (1984, p. 43), expõe a visão de que "[...] é fácil destruir um regime, o difícil é descobrir um regime novo e eficiente que o substitua". O que fica indicado com esse argumento do entrevistado é que a partir da Revolução de 1930 inaugurou-se em um período confuso, de ambiente agitado por uma onda de paixões regionalistas e partidárias.

Com base nisso, logo que assumiu, Vargas implementou uma política de concentração do poder, rompendo com o federalismo da República Velha e promovendo reformas administrativas, o que alterou significativamente as reformas na educação. Tal feito pôde ser evidenciado, segundo Oliveira, Velloso e Gomes (1982), com o Decreto no 19.398 (BRASIL, 1930) e a Lei Orgânica de novembro de 1930 (CAPANEMA, 1952), que estabeleceu a reorganização constitucional do país, que concedia plenos poderes ao Executivo e diluía os poderes 
dos órgãos legislativos como Congresso, Assembleias Estaduais e Câmaras Municipais. Essa centralização dos poderes ainda se verifica com a Lei de Sindicalização, aprovada pelo Decreto no 19.770 , de março de 1931, que vinculava a aprovação do estatuto e o reconhecimento dos sindicatos pelo Ministério do Trabalho (OLIVEIRA; VELLOSO; GOMES, 1982).

Para alguns autores, a Lei de Sindicalização representava a ideia "da cooperação harmoniosa e quase automática do poder público com o povo" (OLIVEIRA; VELLOSO; GOMES, 1982, p. 68). Em contrapartida, é possível apresentar uma contraposição a este argumento em autores como Antunes (1982), o qual defende que a legislação representou um momento estrategista do governo, já que houve ataque dos sindicalistas que, ao rejeitarem qualquer presença estatal nas suas organizações sindicais afirmaram, em seus periódicos, como no jornal $A$ Plebe, que a lei era uma mera adaptação da Carta del Lavoro de Mussolini disfarçada com o "rótulo falso" de Lei de Sindicalização (p. 105).

Os anos de 1930 inauguraram um período de intensa busca para as soluções dos problemas nacionais, o que seria feito por meio do combate à pobreza, uma das estratégias de ação recorrentes e apoiada em uma discursividade então construída. Houve a necessidade de criar uma política de compensação com a ordenação do mercado de trabalho, com a legislação trabalhista, previdenciária, sindical e, também, na instituição da Justiça do Trabalho (OLIVEIRA; VELLOSO; GOMES, 1982). Assim, ao se querer fazer:

[...] o Brasil renascer das cinzas da República Velha, os representantes e agentes da política estado novista adotaram estratégias de construção de novos significados e, diante da precariedade notória da nova ordem política, estimularam a ritualização de práticas sociais e a disciplinarização das condutas. (SOUZA, 2014, p. 399).

Nesse sentido, com a reviravolta política que veio do próprio governo por meio de uma nova Constituição, em 10 de novembro de 1937 (OLIVEIRA; VELLOSO; GOMES, 
1982, p. 44), evidenciamos as questões trabalhistas daquele contexto a fim de demonstrar com quais estratégias o governo e seu grupo de poder trabalharam para estimular a ritualização de práticas sociais, organizar e disciplinar as condutas da sociedade. Em seguida, discutimos de que modo alterações significativas no mundo do trabalho refletiram na organização da educação escolar e promoveram mudanças nas práticas pedagógicas catarinenses. Já que à escola foi dado o papel de ensinar, no que se refere à conduta

[...] o ideal do cidadão apontava para um trabalhador ordeiro, perfeitamente adaptado e defensor das normas vigentes. Seu perfil era aquele que, além de apresentar comportamentos capazes de propiciar exemplo para os demais, estivesse apto de uma forma ou de outra a emitir através de suas atitudes, preceitos de bom comportamento ou manifestações condenatórias ao desvio social. (CAMPOS, 2008, p. 109).

A Constituição de 1937 veio para conduzir o homem ao trabalho, o que, conforme os discursos em voga do presidente Getúlio Vargas, no ano de 1938, asseguraria uma forma digna de vida ao homem brasileiro (VARGAS, 1938). Segundo as diretrizes da nova Constituição, a condição para se promover a paz e o progresso seria a "[...] transformação do homem cidadão pelo trabalhador, responsável por sua riqueza individual e também pela riqueza da nação" (BRASIL, 1937).

$\mathrm{E}$ ao Estado caberia organizar, conforme art. 61 da nova Constituição "[...] as condições do trabalho, da agricultura, da indústria, do comércio, dos transportes e do crédito, com o fim de incrementar, coordenar e aperfeiçoar a produção nacional" (BRASIL, 1937). Essa intervenção do poder público estatal em ordenar o mercado de trabalho se justificava, segundo uma discursividade engendrada pela necessidade de vencer a pobreza, apontada como causa dos problemas sociais e econômicos do país e decorrentes do imobilismo do Estado.

O trabalho se apresentou vinculado ao ideal de homem na aquisição de riqueza e cidadania: "[...] o trabalho passaria a ser um direito e dever do homem; uma tarefa moral e ao 
mesmo tempo um ato de realização; uma obrigação para com a sociedade e o Estado, mas também uma necessidade para o próprio indivíduo encarado como cidadão" (OLIVEIRA; VELLOSO; GOMES, 1982, p. 152).

Já o art. 137 da nova Constituição (BRASIL, 1937)2 determina que o Estado e os órgãos do governo se encarregariam de organizar e manter os direitos constitucionais da empresa e do trabalhador, conforme a legislação nas seguintes proposições:

Os contratos coletivos de trabalho [...] de empregadores, trabalhadores, artistas e especialistas, serão aplicados a todos os empregados [...] deverão estipular obrigatoriamente a sua duração, a importância e as modalidades do salario, a disciplina interior e o horário do trabalho [...] modalidade do salario será a mais apropriada ás exigências do operário e da empresa [...] operário terá direito ao repouso semanal aos domingos e, nos limites das exigências técnicas da empresa, aos feriados civis e religiosos, de acordo com a tradição local [...] Depois de um ano de serviço ininterrupto em uma empresa de trabalho continuo, o operário terá direito a uma licença anual remunerada [...] Salário mínimo, capaz de satisfazer, de acordo com as condições de cada região, as necessidades normais do trabalho; [...] Dia de trabalho de oito horas [...] O trabalho á noite [...] será retribuído com remuneração superior á do diurno; [...] Proibição de trabalho a menores de quatorze anos; de trabalho noturno a menores de dezesseis, e, em industrias insalubres, a menores de dezoito anos e a mulheres; [...] Assistência medica e higiênica ao trabalhador e á gestante, assegurado a esta, sem prejuízo do salario, um período de repouso antes e depois do parto; [...] instituição de seguros de velhice, de invalidez, de vida e para os casos de acidentes do trabalho.

Podemos afirmar que a nova Constituição ilustrava a ideia de reconstrução educacional daquela sociedade na forma pela qual o Estado brasileiro objetivava a criação de um "homem novo" para o trabalho. Uma evidência disso foi o discurso de Vargas logo após a promulgação da Constituição
2 Transcrito na íntegra, sem correções. 
de 1937, que ratificou e aglomerou em íntima conexão os direitos do trabalhador nos espaços sociais distintos. Além disso, foi tocante às expectativas daquela população que desejava estabilidade econômica e educação para seus filhos:

O meu governo tem-se empenhado em garantir aos trabalhadores, aos que não dispõem de recursos acumulados e vivem ao labor quotidiano, as condições de estabilidade econômica necessária à manutenção da prole. A legislação em vigor e as instituições de previdência coletiva, em promissor desenvolvimento, se completam nos resultados e mostram o acerto de nossa política de valorização do homem de trabalho. (VARGAS, 1938, p. 158-159).

Evidenciamos a preocupação de toda uma mentalidade da época, de se fazer aparecer uma nova política do Estado, com homens novos, conforme observado: "O meu governo tem-se empenhado em garantir aos trabalhadores [...] o acerto de nossa política de valorização do homem de trabalho" (idem, ibidem).

De acordo com Bertonha (2004), para a legitimidade destas leis, emergiu a necessidade de se criar um "novo homem" e uma "nova sociedade", expurgada do liberalismo, da decadência burguesa e do perigo do materialismo marxista; uma sociedade sem divisões, coesa e solidária, e que, em outras palavras, foi chamada de corporativa. Nessa linha de pensamento, no campo educacional, Vargas operacionalizou um discurso que assegurava os direitos à educação dos filhos de trabalhadores:

É preciso que as crianças destes colaboradores anônimos da prosperidade individual sejam devidamente amparadas e, enquanto as mães ganham o pão nas fábricas e oficinas, os filhos pequeninos estejam nas creches, recebendo, com os cuidados higiênicos necessários, alimentação sadia e adequada, e os mais crescidos estudem nos jardins de infância e escolas próprias da idade. (VARGAS, 1938, p. 158-159).

Centros de saúde, ambientes de trabalho, instituições escolares e outras instituições sociais foram lugares de 
investimentos estratégicos direcionados aos sentidos do homem, para dotá-lo das qualidades necessárias à conservação do sentimento de brasilidade. Esse sentimento, capaz de promover a integração do indivíduo à nação, poderia ser atingindo a partir de uma série de requisitos em que estavam incluídos dotar os sentidos de habilidade e disciplina para o trabalho e, também a educação de caráter cívico, voltada para a afirmação de uma identidade nacional. Tais acontecimentos evidenciaram um sentimento de abrasileiramento no cenário social:

Enquanto o brasileiro não se abrasileirar é um selvagem. Os tupis nas suas tabas eram mais civilizados que nós em nossas casas de Belo Horizonte e São Paulo. Por uma simples razão: não há uma Civilização. Há civilizações [...] Nós, imitando ou repetindo a civilização francesa, ou a alemã, somos uns primitivos, porque estamos ainda na fase do mimetismo. (SCHWARTZMAN; BOMENY; COSTA, 2000, p. 80).

É importante mencionar que os movimentos oficiais de Estados não foram orientações únicas e exclusivas para aquilo que estava na sociedade visando à construção de uma identidade nacional. Partindo do pressuposto de que o poder não aparece de forma centralizada, mas que se manifesta, das mais diferentes maneiras, nos diversos pontos do tecido social, houve uma série de determinantes, que nos indicam que o projeto de abrasileiramento da população não estava centrado somente no governo de Getúlio Vargas. Isso porque a sociedade já expressava pensamentos nacionalistas através de movimentos culturais em períodos que antecedem o governo getulista, por exemplo, no acontecimento da Semana de Arte Moderna em 1922. Ademais, é importante mencionarmos que o projeto de nacionalização da cultura:

[...] estava em gestação desde a década de 1920, com as diversas reformas em termos regionais que se sucederam nesse período. A possibilidade histórica de sua realização, no entanto, se dá na década de 1930, com a proposta de criar um homem moderno, 
de processar a chamada reconstrução nacional. (SANTOS; MUELLER, 2010, p. 266).

Além disso, Campos (2008, p. 45) ratifica a ideia de que não foi somente a imprensa que exerceu uma ação que regulamentou a conduta dos indivíduos. As falas do interventor, secretariado ou intelectuais da época, ao emitirem preceitos de caráter moral, constituíram veículos de modificação de comportamentos (CAMPOS, 2008). Esses discursos, como jogos estratégicos de dominação e resistência, evidenciam projetos sociais articulados por grupos de atuação política organizados por categorias profissionais diferenciadas e por representantes dos mais diversos segmentos da população. Assim, percebemos que o poder não está somente concentrado no Estado, mas é uma teia de relações que envolve diversificadas instituições da sociedade civil, e é exercido sobretudo por incitar, envolver, mobilizar, obrigar a dizer (DALLABRIDA, 2003, p. 12).

A moralidade do "ser brasileiro" manifestada no âmbito da sociedade, segundo tais perspectivas, teve como ponto de referência a adoção de comportamentos socialmente desejáveis, o que incluía uma nova internalização de uma maneira de sentir. Isso significaria que agrupamentos populacionais no Estado de Santa Catarina, por hipótese, foram despertados com "sensibilidades" que passaram pela introjeção do amor pela pátria como sentimento possível de ser atingido após os indivíduos receberem formação de caráter cívico. Dessa forma, a brasilidade, além de constituirse em elemento que estabelecia distinções entre habitantes do território brasileiro e os de fora, apresentava-se como requisito essencial que garantiria integridade ao Estado Nacional (CAMPOS, 2008, p. 112).

Ademais, vale lembrarmos de que, durante este período, no contexto educacional do Brasil, disseminou-se entre segmentos da sociedade a crença de que na educação residia a solução dos problemas que identificavam. Esse entusiasmo no campo da educação condensavam expectativas diversas de 
controle e modernização social, cuja formulação mais acabada se deu no âmbito do nacionalismo.

\section{O romantismo na educação}

Jorge Nagle (2004) nomeia a base do movimento que preconizava a construção da brasilidade como forma de conduta moral dos indivíduos de "entusiasmo pela educação". Isso porque tal movimento de pertencimento e identificação com a cultura brasileira apenas seria possível com a disseminação da educação popular. Segundo a autora "o entusiasmo pela educação" ocorreu em um momento de decepção dos republicanos com o período pós-Republicano, o que fez com que se pensasse não mais em uma política de desvinculação e independência, mas sim no Brasil e no brasileiro (NAGLE, 2004, p. 263).

Dessa forma, a percepção "romântica" dos problemas da sociedade brasileira e de suas soluções resultou em uma superestimação do processo educacional: “[...] regenerador do homem ele é, consequentemente, o regenerador de toda a sociedade" (NAGLE, 2004, p. 263).

Assim, os quadros do pensamento germinado no âmbito daquela sociedade indicavam que: "[...] a ignorância reinante é a causa de todas as crises; a educação do povo é a base da organização social, portanto, o primeiro problema nacional; a difusão da instrução é a chave para a solução de todos os problemas sociais, econômicos, políticos e outros" (SERVA, 1998 apud NAGLE, 2004, p. 63).

Um exemplo disso, representado pela imagem a seguir, é o desejo republicano, que se estendeu na década de 1930, pela transformação dos indivíduos ignorantes em cidadãos esclarecidos. A árvore, plantada pelo próprio Getúlio Vargas no Colégio Estadual Getúlio Vargas em 12 de março de 1940 na cidade de Florianópolis nos faz refletir, de maneira metafórica, sobre esta expectativa de transformação, por meio da escola, das novas gerações: "germinaria e produziria bons frutos". 
Figura 1 - Árvore plantada em 12 de março de 1940.

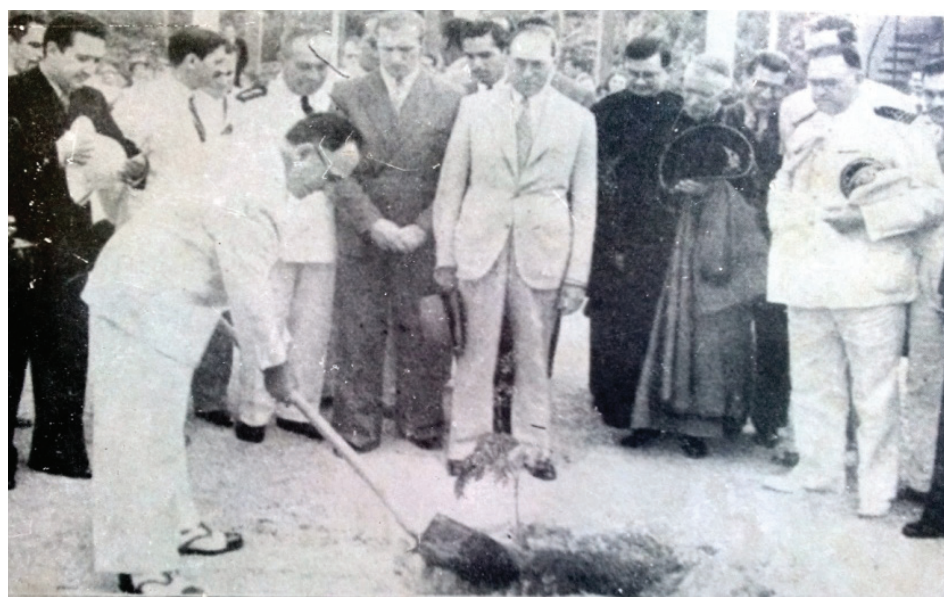

Fonte: Colégio Estadual Getúlio Vargas, Florianópolis.

Parte do projeto, para a chamada reconstrução nacional, foi identificada nas políticas pensadas no plano da educação, fundamentadas pelo Ministério da Educação e Saúde e que foram, em boa parte, comandadas por Gustavo Capanema. As discussões sobre as questões educacionais destinadas à formação do novo homem nas escolas apresentam numerosas frentes e variadas propostas pedagógicas. Os currículos foram pensados com especial cuidado, principalmente no que referia aos métodos de ensino. Assim, destacamos a situação das políticas educacional e cultural no Brasil daquele período com a atuação de Gustavo Capanema, ministro da Educação e Saúde de Getúlio Vargas no Governo Constitucional e Estado Novo (1934-1945).

Capanema foi considerado defensor da cultura e das artes. Juntamente com sua equipe, fez a reforma do ensino secundário, ajudou na organização da Universidade do Brasil, a implementar o ensino industrial e a criar o Patrimônio Histórico e Artístico Nacional, fomentando programas nacionais de saúde pública, entre tantas outras iniciativas. Construído em sua gestão, o edifício do Ministério da Educação com linhas paisagísticas e arquitetônicas da modernidade, destacou-se por representar um avanço para a época, por ser exemplo de 
uma nova estética ainda em gestação. (SCHWARTZMAN;

BOMENY; COSTA, 2000),

Em 26 de julho de 1934, dez dias após a eleição de Vargas para a presidência da República pela Constituinte, Capanema foi efetivamente nomeado para a pasta da Educação e Saúde Pública (SCHWARTZMAN; BOMENY; COSTA, 2000). Articulador da legitimação do sistema político, defensor do "Estado forte e intervencionista", apoiador da ditadura e dos princípios nacionalistas do Estado Novo, Capanema responsabilizou-se por dar novos rumos e orientações para a organização do sistema educacional brasileiro, no que o governo de Santa Catarina também investiu, necessariamente e em decorrência dos ditames nacionais.

O foco principal era o ensino público abrangente; porém, rigorosamente controlado. Assim, o legado de Capanema marcou um período de forte controle e fiscalização da ordem social através da educação. $\mathrm{O}$ desafio era concretizar uma sociedade homogeneizada com base em uma forma nacional, como ocorreria em vários países do mundo, especialmente naqueles do continente europeu como a Itália e a Alemanha, por exemplo. E a educação estabeleceu-se com o intuito de formar cidadãos "saudáveis, produtivos, dóceis e obedientes" (DALLABRIDA, 2003, p. 14).

No plano configurado pelas políticas de centralização e modernização da máquina pública, Gustavo Capanema sancionou medidas em seu projeto consideradas autoritárias. Sobre os regimes autoritários, Bobbio, Matteucci e Pasquino (1998, p. 101) esclarecem que:

[...] regime autoritário é sistema político com pluralismo político limitado e não responsável; sem uma ideologia elaborada propulsiva, mas com mentalidade caraterística; sem uma mobilização politica intensa e vasta, exceção feita em alguns momentos de seu desenvolvimento; e onde um chefe ou até um pequeno grupo exerce o poder dentro dos limites que são formalmente mal definidos, mas de fato habilidosamente previsíveis. 
Um exemplo de mudança que teve teor autoritário no

3 A natureza da bibliografia com que dialogamos estabelece vínculos entre a questão da imigração europeia para o Brasil, a fixação dessa população e os conflitos culturais e políticos gerados pela presença desta população tida como pouco nacional e até mesmo ameaçadora à nação brasileira que emergiria na modernidade.
Ministério Capanema foi a decisão na resolução educacional em torno das "escolas alemãs" escolas e conferiu maior "tranquilidade" ao governo, já que as escolas estrangeiras representavam ameaça ao projeto de nacionalização. Capanema contribuiu e incitou, ainda, o fechamento de outras instituições de caráter étnico dirigidas pelos imigrantes alemães e seus descendentes, consideradas perigosas "aos olhos" do governo. Atuou no fechamento de clubes de canto, ginástica, bolão, entre outras agremiações estrangeiras (SANTOS; MUELLER, 2010, p. 266).

Por ter sido a escola vista pelo ministério como caldo de cultura para a tarefa de inculcação do nacionalismo, disseminou as cartilhas de "Getúlio Vargas para Crianças" que se apresentavam como suporte de propaganda destinada às instituições escolares, principalmente as do sul do Brasil. Um despertar desse sentimento pretendido pelo Estado Novo:

A implementação da proposta nacionalista, materializada nas práticas pedagógicas, era orientada pelo Departamento de Educação, representante do governo e veículo inoculador de seus escopos ideológicos homogeneizadores. De fato, recursos diversos foram utilizados pelos professores, diante da insistente exigência e criteriosa verificação do atendimento às "recomendações" do serviço de inspeção escolar, em cumprimento às determinações legais. (SANTOS; MUELLER, 2010, p. 270).

A modernidade defendida pelo governo de Vargas (1930-1945) estava projetada para atender aos objetivos de nacionalização e de abrasileiramento, em expressões com tom de fascismo, instituído pelo governo especialmente a partir do Estado Novo (1937-1945). A educação escolar foi usada a serviço desse ideário. E esse é um argumento que vem sendo trazido na contemporânea historiografia, notadamente com base nos estudos realizados por Santos $(2010,2014)$ e por Santos e Mueller (2010), que são focados no cenário educacional de Santa Catarina durante a Era Vargas. 
Então, ao procurarmos nos indivíduos o que vem a ser um sentimento nacional, leva-nos a pensar a edificação dessa entidade histórica. Utilizando referenciais objetivos, encontramos um Estado que, com espectros nacionalistas, toma as culturas preexistentes, as transforma e as inventa frequentemente em nações (imaginário comum). Essa atuação de Vargas à frente do Estado brasileiro destinaria ao governo um projeto político revestido de autoritarismo e nacionalismo influenciado pelas Forças Armadas e que, por meio da escola, buscaria modificar, no plano da cultura, o "povo" em "nação brasileira".

Sob tal prisma e para propósitos de análise, adotamos uma conceituação de "nacionalismo" que seria uma condição necessária para o surgimento das nações. Ou seja, "o Estado nacional gera o Nacionalismo, na medida em que suas estruturas de poder, burocráticas e centralizadoras, possibilitam a evolução do projeto político que visa à fusão de Estado e nação, isto é a unificação, em seu território, de língua, cultura e tradições" (BOBBIO; MATTEUCCI; PASQUINO, 1998, p. 799).

Nesse sentido, haveria investimento do Estado brasileiro no esforço de "unificar" em seu território essa diversidade de grupos, cada qual ainda com sua língua, cultura e tradições. Tal movimento se daria mediante uma formação nacionalista. Pela abordagem teórico-metodológica tratada, estimamos que a uniformidade pretendida se apresentaria, também, na operacionalização dos exercícios escolares ${ }^{4}$ que gradativamente tomavam conta do cotidiano dos habitantes de Santa Catarina, cristalizando-se em hábitos e costumes de uma sociedade em modernização, tendo a escola como locus de realização de atividades curriculares amiúde propostas e com resultados alinhados ao ideário de governo.

\section{Educação e etnicidade no estado de Santa Catarina}

Nascidos no Brasil, não há, em face do nosso estatuto político, luso-brasileiros, teuto-brasileiros, ítalobrasileiros, ou quaisquer outras combinações raciais, que desvirtuem o sentido político da cidadania brasileira, que é uma só, indivisível, e homogênea.

\section{A seguir, apresentaremos esta análise com a investigação de fontes que apresentam práticas pedagógicas nas instituições escolares de Santa Catarina.}


(D'AQUINO, 1993 apud CAMPOS, 2008, p. 185, grifos nossos).

Atualmente, a população de Santa Catarina é constituída por diversas etnias, sendo predominantes os descendentes de portugueses, alemães, italianos e, em menor proporção os poloneses, indígenas, africanos e orientais. Povos estes que comportam expressões culturais manifestadas em hábitos alimentares, festas, formas de organização social, sobrenome e "sotaques" que revelam singularidades de uma trajetória histórica que caracteriza este Estado.

A partir do processo de colonização, na segunda metade do século XIX, Santa Catarina deixou de ser passagem para tropeiros do sul que procuravam pelo centro do país e passou a constituir-se espaço de moradia fixa. No povoamento no sul do Brasil, conforme salienta Dallabrida (2001), constituíramse algumas características da escola influenciadas pelos negros, poloneses, italianos e alemães, cuja contribuição destes povos para a educação escolar em Santa Catarina na passagem dos séculos XIX e XX tornou a história da educação catarinense rica em suas particularidades e especificidades.

Para os negros, a Lei do Ventre Livre, de 1871, foi um marco para a educação. Por meio dessa lei, todas as crianças nascidas de escravas - os ingênuos - a partir daquele ano, seriam livres. Entretanto, como até os oito anos de idade as crianças permaneciam sob a autoridade do senhor de suas mães, aquelas continuavam reféns da escravatura, pois o senhor não tinha responsabilidade de zelar pelos menorzinhos. Encerrada essa etapa, o proprietário da mãe poderia optar por entregar a criança ao governo mediante indenização ou permanecer com esta até ela completar 21 anos de idade; porém, ela deveria prestar serviços em troca de subsistência. As crianças entregues à província poderiam ser destinadas a instituições ou a associações como asilos agrícolas e casas de caridade. Contudo, os proprietários preferiam ficar com as crianças até completarem 21 anos, do que entregá-las ao governo da Província, pois estas executavam serviços em sua propriedade. 
Novamente, destacamos que a escola foi uma forma que as elites encontraram de normatizar, ordenar e homogeneizar as massas, também como meio de ter controle sobre elas.

Aos poloneses, a escola foi o principal instrumento de manutenção do poloniismo ou polonidades, expressas na cultura, religião e particularidades sociais trazidas da Polônia. Com o desinteresse estatal pela educação, os poloneses, assim como as demais culturas europeias construíram suas próprias escolas, mantendo os professores, pois acreditavam que a educação poderia preservar a sua cultura de origem. A expressão comum generalizada até hoje "andar na escola" (TOKARSKI, 2003, p. 101), justificava a permanência das crianças em idade escolar na escola, mesmo que sob duras penas; afinal, ali aprendiam os rudimentos de linguagem e aritmética. Só que, tomadas pelo golpe da campanha de nacionalização, as "escolas polacas" se tornaram espaços de arbitrariedade e violência; por isso, durante o período ditatorial do governo de Getúlio, foram suprimidas.

Já as escolas italianas costumavam funcionar na casa do professor, que era uma pessoa integrante da comunidade, com certa experiência em educação. Às vezes, as capelas também serviam de escola ou, então, as escolas eram construídas ao seu lado. Os professores recebiam salários diferentes em cada escola, e que variava conforme o valor que cada comunidade podia pagar. Contudo, em razão desta proximidade entre escola e religião predominantemente católica, as instituições se tornaram escolas paroquiais frequentadas por filhos de italianos, e o ensino era ministrado em língua italiana ou em algum dos dialetos. Por vezes, essas escolas eram fundadas por algum padre e com o apoio dos colonizadores italianos. Contudo, nem o fechamento das escolas italianas na Primeira Guerra Mundial, nem o Decreto do governador Felipe Schmidt que determinava que as aulas deveriam ser dadas em língua portuguesa conseguiram eliminá-las definitivamente, uma vez que sobreviveram até cerca de fins da década de 1930.

Por sua vez, quando os imigrantes alemães começaram a se estabelecer em Santa Catarina, o sistema escolar local 
encontrava-se em um estágio incipiente (WEREBE, 1997). Império e Província não se encontravam em condições de atender a essa necessidade, e a educação era algo totalmente ausente; logo, a iniciativa deveria partir dos próprios colonos.

Nos primeiros anos de Brasil, a vida dos imigrantes teutos, assim como dos demais, caracterizava-se por uma árdua labuta pela sobrevivência. A improvisação seria uma característica dessas escolas nos primeiros tempos - a estrutura dos conteúdos se ajustava ao local, ao professor e à experiência cotidiana dos colonos, que estabeleciam o "currículo" para seus filhos. Os anos de isolamento, sem vínculo com o Estado, fizeram com que se desenvolvesse certa autonomia. A organização escolar interna era tal que as diretorias dessas comunidades escolares preferiam manter a independência, temendo aspectos negativos com o enquadramento vindo do Governo.

Assim, a organização da escola de cada comunidade fez com que se desenvolvesse um tipo de professor sui generis no meio teuto-catarinense. E o trabalho do professor não se limitava apenas ao ensino, pois dele se esperava que também dirigisse o coro da igreja e organizasse as atividades festivas, por exemplo. Com frequência, os docentes eram solicitados a atuarem nas situações mais diversas; e, em algumas das colônias, não gozavam de estabilidade, podendo ser contratados e dispensados conforme a comunidade julgasse oportuno. E o prestígio, em alguns locais, dependia mais da forma como os professores se desincumbiam das demais funções que deles esperavam do que do desempenho como professor.

No Brasil, apesar da Constituição Republicana de 1891 buscar assegurar o ensino leigo e aconfessional nos estabelecimentos escolares, a escola era um espaço de insuflar as ideias republicanas de adestramento dos corpos para o mundo da ordem, trabalho e progresso. Ou seja, era onde:

A intervenção sobre corpo dos alunos tratava minuciosamente dos gestos e movimentos a serem executados, estendendo-se para a implementação de dispositivos de regulamentação do uso do tempo. A disciplina escolar equiparava-se àquela levada a 
termo em instituições como o quartel, a penitenciária ou o convento, inserindo-se numa fobia de vigilância que permeou todos os espaços sociais [...]. Essas formas de controle assemelharam-se às desenvolvidas na produção fabril e constituíram-se em práticas eficazes para preparar futuros trabalhadores se disciplinar a vida de todo o conjunto da sociedade. (CAMPOS, 2008, p. 187).

A escola desejada por este projeto republicano requeria o sequestro das crianças para instruí-las no mundo do trabalho e no respeito a seus superiores. Desejava-se transpor para o Brasil os códigos de "civilização europeia" e o aprimoramento da mão de obra para sedimentar uma identidade nacional.

No início do século $\mathrm{XX}$, as elites republicanas catarinenses afirmaram o desejo de organizar o ensino com base no modelo adotado pela província de São Paulo em 1893 (FIORI, 1991). Mais tarde, objetivaram a construção da normalização nacionalizada devido à formação da sociedade estadual e aos jogos de poder, após a ruptura provocada pela Revolução de 1930 (DALLABRIDA, 2003).

A questão da nacionalização era candente no território catarinense graças à presença maciça de imigrantes, especialmente alemães, italianos e poloneses, organizados em instituições comunitárias, como as escolas. De acordo com Dallabrida (2003), até 1930 os investimentos públicos em prol da nacionalização foram realizados de forma mais amena, por exemplo, por meio da introdução da disciplina língua alemã no currículo das escolas normais e complementares que formavam as professoras primárias. Essa estratégia foi introduzida pelo professor Orestes Guimarães, principal responsável pela reforma do ensino catarinense nos anos de 1910 e 1920, com o intuito de abrasileirar, através da educação, os imigrantes.

A contratação do professor paulista Orestes Guimarães, em 1910, pelo governo Vidal Ramos estreitou os vínculos entre a Reforma do ensino em Santa Catarina e as ações pedagógicas que se vinham perdurando no cenário de São Paulo. Em detrimento disso, a apropriação de um modelo paulista para educação ignorou, em vários aspectos, os 
percursos históricos de educação e etnicidade, específicos de Santa Catarina, desconsiderando os contextos que fizeram emergir a necessidade de criação das escolas nas comunidades de imigrantes que, diferentemente de São Paulo, ocorreu em épocas distintas.

Assim, promover a reforma no sistema educacional, a exemplo da Europa e dos Estados Unidos da América, significaria inaugurar um novo sistema de pensamento, transformador da sociedade brasileira. Sendo essa sua principal característica, Orestes Guimarães buscou realizar a reforma educacional, quanto à questão de pretensa inovação, pelo viés do método de ensino intuitivo. Partimos da premissa de que eram vistos por Orestes também sob uma perspectiva nacionalizadora.

É importante que se discuta elementos acerca da proposta de nacionalização do ensino na Reforma Orestes Guimarães, a qual pode ser analisada em três fases de implementação: no primeiro momento, enquanto Guimarães era diretor do Colégio Municipal de Joinville, é comumente chamada de "Pedagogia da coexistência cultural"; em seguida, quando dirigiu a reforma da instrução pública do estado, ficou conhecida como fase de assimilação e formação do ethos nacionalista ou "fase de infiltração" e o último, quando foi inspetor federal das escolas subvencionadas pela União em Santa Catarina.

5 Segundo Fiori(1991), “[...] nos primeiros tempos do período republicano, o panorama geral da instrução pública catarinense era desolador, o que era reconhecido abertamente pelo Governador" (p. 77). As escolas primárias públicas estaduais eram inadequadas; faltavalhes desde o mobiliário até o material didático. "Contudo, [...] cresciam em número e aumentavam, também, a frequência e a matrícula escolar" (p. 78).
Foram investigados aspectos referentes ao prescrito de Orestes Guimarães para o ensino da escola pública, incluindo programa, disciplinas de educação cívica e conteúdos previstos em seu relatório enquanto diretor do Colégio Municipal de Joinville nos anos de 1907 e 1909. No final do século XIX e início do século XX, a escola primária em Santa Catarina era, em boa parte, subsidiada por associações escolares de cunho diverso, com pouco ou quase nenhum apoio do Estado 5 . E, embora sem a presença efetiva do Estado no início do século XX, é possível afirmar que já existia um "sistema escolar", ou seja, uma associação de escolas, sobretudo elementares, que 
funcionavam por iniciativa das próprias comunidades e que por estas eram mantidas.

Com características de escolas comunitárias, notadamente as escolas fundadas por imigrantes alemães mantiveram conservados traços de sua cultura e, ao mesmo tempo, supriram a carência do ensino público: "os imigrantes trataram de organizar sua própria escola, como forma de prover seus filhos da educação devida" (LUNA, 2000, p. 19).

Essas escolas, construídas nas comunidades de imigrantes teutos, organizadas e instaladas no Estado, eram vistas com certo temor por parte do governo brasileiro, já que, no século XX, mais especificamente em Santa Catarina, ganhou voz o discurso de construção de uma nação única, na qual deveriam prevalecer os sentimentos de abrasileiramento (SANTOS, 2010).

Analisar as transformações das escolas de Santa Catarina nos primeiros tempos do republicanismo ${ }^{6}$ envolve verificar, notadamente em uma conjuntura histórica, as medidas do governo tomadas frente às escolas estrangeiras do Estado, o que fez com que se instituíssem reformas e uma série de ações políticas e pedagógicas de caráter centralizador e autoritário.

Dentre as reformas da instrução pública em Santa Catarina no período da República, destacamos a reforma do professor Orestes Guimarães, através da Lei no 846, de 11 de outubro de 1910 (GUIMARÃES, 1929). Tal reforma objetivou a modernização da escola e introduziu os princípios científicos na cultura e nos materiais escolares, bem como na formação de professores, especialmente no que se refere às práticas didáticas e à instrumentalização de técnicas. Estes últimos foram verificados em discursos para os métodos de ensino, escorados na legislação. Os objetivos de Orestes para as mudanças no método visavam a doutrinar, moldar as crianças para um espectro de mentalidade coletiva: a ideia de pertencimento à nação.

No início do século XX, o professor Orestes Guimarães foi chamado ao Estado de Santa Catarina para assumir a função de diretor do Colégio Público de Joinville. Sua ação
6 Fiori (1991) argumenta que as transformações no ensino em Santa Catarina no século XX podem ser estudadas a partir do período do governo Vidal Ramos. 
possuía características de inclusão de saberes como brasilidade e cultura nacional, que deveriam ser desenvolvidos nas escolas de acordo com a abordagem teórica do ensino intuitivo. Concatenando com esta ideia, Teive (2003, p. 29) aponta que:

Orestes Guimarães acreditava que o caminho para mudar a escola, convertendo-a em uma instância civilizadora e inculcadora de novos valores e normas de comportamento, era organizá-la e regê-la sob os pressupostos do método de ensino intuitivo ou lições de coisas, considerando a encarnação do verbo modernizar.

Assim, enquanto diretor, Guimarães elaborou um relatório apresentado para o superintendente Municipal de Joinville. Transferiu, ainda segundo o seu projeto, algumas ideias para a reorganização da disciplina de História para a escolarização primária em Santa Catarina, que, naquele momento, procurava ser contributiva para a nacionalização gradual da cultura da população escolar e em geral.

Entretanto, é importante mencionar que somente por volta de 1911, com a Reforma do Governo Vidal Ramos, os grupos escolares foram criados com turmas seriadas em Florianópolis, Joinville, Laguna, Lages, Blumenau e Itajaí. $\mathrm{O}$ que fez representar um tipo de instalação escolar que visava a atender ao chamado republicano de edificação nacional. À escola, foi direcionado o papel de configurar uma identidade nacional mediante uma representação que melhor atendesse ao projeto da República, o que a tornou um local de estímulo à segregação de outras identidades étnicas que ali existiam.

Foram implementados os aspectos de ensino simultâneo, ensino graduado e educação dos sentidos que se depreendia do chamado "método de ensino intuitivo" ou "lições de coisas" (TEIVE, 2003). Nas primeiras escolas públicas de ensino primário, o importante era "aprender a escrever, ler e contar". Além da leitura e da escrita, abordavam-se conteúdos como as quatro operações de Aritmética, bem como as doutrina cívica.

Cabe mencionar a questão da doutrina cristã, que aparecia relacionada à formação cívica na base do ensino 
escolar brasileiro. Ressaltamos que encontramos aspectos da política de Vargas no interior do cotidiano escolar semelhantes aos de países europeus para a propagação da crença na religião predominantemente católica. Queremos chamar atenção, por exemplo, para o projeto totalitário de Hitler na Alemanha que gerou fortes alianças entre as instituições do governo com o campo religioso. $\mathrm{E}$ tais aspectos estavam intrinsicamente relacionados ao papel atribuído às instituições escolares de Santa Catarina para reproduzir, na infância, os valores religiosos de "regeneração social", em prol da família e sociedade, evidenciada nas seguintes orientações de Rui Barbosa (1950, p. 554):

[...] comece essa educação bem cedo [...]. Em principiando a se revelar no menino o senso moral, é para logo encaminhá-lo, educando-o. As impressões que mais duram e mais fundo se enraízam são essas cuja origem nos esqueceu e embebemos inconscientemente quando crianças. Nesse período, é suscetível a índole infantil de adquirir forte propensão para o bem. Não há então obstáculos, que aplainar, nem nada que desaprender; as inclinações são suaves e amolgáveis.

Essas instruções, direcionadas ao professor para que se trabalhasse de forma "suave e amolgada" com a criança a fim de que esta adquirisse "inconscientemente as impressões que mais duram", foram identificadas no manual de ensino "Lições de Coisas" traduzido por Barbosa (1950), o que ajudou a refletir que tal feito demonstraria tentativas de "docilização dos sentidos", contando com o ensino dos deveres religiosos e patrióticos.

A busca pelo patriotismo brasileiro proporcionou a soma de um conjunto de coisas materiais e imateriais passadas, presentes e futuras, e pretendia firmar as tradições brasileiras. A identificação nacional seria forjada na escola em função dos interesses do Novo Estado, o qual fazia nascer, com base em novas determinações, a persuasão de normas e valores padronizados e impostos por aquele contexto. 
Os assuntos de unificação étnica, politica, religiosa foram, nessa perspectiva, elementos de discussão do poder constitutivo estatal e perpassavam as questões educacionais entre os grupos étnicos que ali habitavam. Assim, os poderes institucionais passaram a se expressar em termos disciplinares, persuasivos e onipotentes, abrindo espaço para a afirmação da unidade nacional e a construção de culturas identitárias e unificadoras, por consequência, excludentes.

O projeto do Estado Novo apregoava, no discurso dos poderes institucionais, a necessidade de construção e a defesa de uma nação nova. O que mobilizava ingredientes típicos da homogeneização vinculados às questões referentes à cidadania.

\section{Algumas considerações}

Se uma parte dos comportamentos sociais é resultante de um processo de aprendizado - um aprender que diz respeito ao viver coletivamente em contato com os outros -, consideramos relevante mencionar que o termo "cidadania" foi pensado nos discursos como legitimador de um comportamento social. E à escola foi dado o importante papel persuasivo de crença nesse processo.

Os discursos que circulavam para reconstrução de uma identidade nacional comprometiam a chamada cooperação de instituições sociais variadas, e à escola foi atribuído um papel que visava, entre outras coisas, à unificação das etnias e, por isso, voltado à regeneração social e à recondução dos sujeitos a uma postura de identificação brasileira.

Emergia, como revelam vários momentos do autoritarismo, a questão étnica como ingrediente. A questão da etnia esteve sistematicamente marcada pelo ambiente da imigração europeia de influência alemã e italiana na conformação da cultura local em Santa Catarina. Entre as várias levas de imigração, 1824, 1930 e 1940, constituiuse especialmente a configuração de certos segmentos do sistema escolar. E, pela bibliografia abordada, notamos que o atendimento à infância na escola primária exerceu uma função essencial para os imigrantes. 
Nesse sentido, as preocupações com a educação interessaram-se pela ampliação do campo de influência da escola com as famílias, a fim de promover a unificação do uso da língua e dos costumes. Tais questões teriam sido colocadas entre os governos catarinenses, em especial pelo governo Nereu Ramos, como indicou Campos (2008).

$\mathrm{Na}$ análise desenvolvida, o projeto de regeneração de Santa Catarina do século XX foi acompanhado das políticas de assistência estatais que teriam deixado de ser um sistema de ajuda aos pobres para se converterem em um instrumento a serviço da consolidação da indústria.

Além disso, como este artigo se voltou para discussão das transformações operadas no espaço escolar, procuramos denunciar a concepção de escola enquanto instituição transmissora de conhecimento que afirmava sua noção de vigilância permanente, com vistas a promover uma adequação dos comportamentos ou a domesticação dos seus alunos.

Partiu-se do argumento de que a escola ganhou, neste processo, a importância de ser uma instancia social a mais passível de promover a conformação dos indivíduos, garantindo, no espaço urbano, a disciplina necessária às novas formas de vida e de trabalho em expansão em Santa Catarina. Salientamos, ainda, que, no Brasil, entre os anos de 1930 e 1940, os esforços políticos se voltaram para o sentido pedagógico de "assimilação" dos estrangeiros à cultura brasileira, com o apoio do exército. Isso porque tais inquéritos intentavam dissuadir os civis de promoveram manifestações que ferissem o projeto político de construção da nacionalidade, iniciado em 1930, e materializado no Estado Novo, na tentativa de afirmação da identidade nacional, metamorfoseado em homogeneização do provo brasileiro e buscando apagar as diferenças regionais, étnicas, de idiomas.

Contudo, essas décadas marcadas pelos discursos de construção dos conceitos imaginários de nação e pátria nos estrangeiros, significou a multiplicidade de diferenciadas manifestações socioculturais próprias do sul do Brasil devido à sua diversidade populacional. Isso se passou com o crescimento da indústria na sociedade catarinense. 
Logo, é possível atrelar os objetivos do projeto de nacionalização com a crescente industrialização neste Estado, visto que, conforme explicitamos no texto, entre os anos 1920 e 1940, o crescimento industrial atingiu com mais eficácia as regiões de colonização alemã, as quais já estavam se industrializando desde o final do séc. XIX.

Essas mudanças tenderam a ser explicadas em uma perspectiva socioeconômica, a partir dos capitais que foram acumulados tanto pelas trocas efetuadas em economias camponesas quanto pela exploração dos trabalhadores anteriormente ligados a pequenas propriedades domésticas, agropecuárias e artesanais. $\mathrm{E}$ tais transformações teriam sido as bases para o surgimento de uma produção têxtil e de mobiliário. Os anos 1930 marcaram uma nova etapa no desenvolvimento econômico de Santa Catarina, sobretudo com um movimento de dinamização da indústria.

Conforme mencionamos, com os processos de industrialização, tais mudanças ocasionadas na esfera política, social e econômica provocaram necessidades de transformações na educação, o que fez com que o governo elaborasse um projeto político que almejasse a garantia de uma juventude engajada na construção da nação e que, também, disciplinasse para o trabalho a massa popular.

Notadamente na primeira fase governada por Vargas, houve medidas que atingiram as instituições escolares do governo brasileiro em relação ao sul do Brasil. Prova disso é a evidência de que a questão da escola constituiu-se em uma das faces de assistencialismo de Nereu Ramos devido à importância de assumi-la como o novo lugar da criança e da família na sociedade moderna e industrial.

Paralelamente às alterações fabris pelas quais Santa Catarina passou nesse período, resultou uma nova configuração dos espaços urbanos e na regeneração dos hábitos e comportamentos da população. Enfim, manifestouse uma tendência em "aperfeiçoar" e "ampliar" a instituição escolar como único meio eficiente de educação (CAMPOS, 2008, p. 180). 


\section{Referências}

Revista Grifos 169

ANTUNES, Ricardo C. Classe operária, sindicatos e partido no Brasil: um estudo sobre a consciência de classe: da revolução de 30 até a aliança nacional libertadora. São Paulo: Cortez Editora, 1982.

BARBOSA, Rui. Lições de Coisas - Vol. XIII, Tomo I, 1886. In: MINISTÉRIO DA EDUCAÇÃO E SAÚDE PÚBLICA. Obras Completas de Rui Barbosa. Rio de Janeiro: Ministério da Educação e Saúde Pública, 1950.

BERTONHA, João Fábio. Fascismo, nazismo, integralismo. São Paulo: Ática, 2004.

BRASIL. Constituição (1937). Constituição dos Estados Unidos do Brasil, 10 de novembro de 1937. Diário Oficial da União, Brasília, DF 10 nov. 1930. Disponível em: <http://www.planalto.gov.br/ ccivil_03/constituicao/constitui\%C3\%A7ao34.htm>. Acesso em: 10 abr. 2016.

BRASIL. Decreto no 19.398, de 11 de novembro de 1930. Institue o Governo Provisório da República dos Estados Unidos do Brasil, e dá outras providencias. Diário Oficial da União, Brasília, DF 11 nov. 1930. Disponível em: <http://legis.senado.gov.br/legislacao/ ListaPublicacoes.action?id=37246\&>. Acesso em: 10 abr. 2016.

BOBBIO, Norberto; MATTEUCCI, Nicola; PASQUINO, Gianfranco. Dicionário de política. 11. ed. Brasília: Editora Universidade de Brasília, 1998.

CAMPOS, Cynthia Machado. Santa Catarina, 1930: da degenerescência a regeneração. Florianópolis: Ed. UFSC, 2008.

CAPANEMA, Gustavo. Exposição de motivos da lei orgânica do ensino secundário. In: NÓBREGA, Vandick Londres da. Enciclopédia da legislação do ensino. Rio de Janeiro: Revista dos Tribunais, 1952. p.22-28

DALLABRIDA, Norberto. A fabricação escolar das elites: o Ginásio Catarinense na Primeira República. Florianópolis: Cidade Futura, 2001.

DALLABRIDA, Norberto (Org.). Mosaicos de Escolas: Modos de Educação em Santa Catarina e Primeira República. Florianópolis: Cidade Futura, 2003.

FIORI, Neide Almeida. Aspectos da evolução do ensino público: ensino público e política de assimilação cultural no Estado de Santa 
Catarina nos períodos Imperial e Republicano. 2. ed. Florianópolis: Ed. da UFSC, 1991.

GUIMARÃES, Orestes. Nacionalização do Ensino Primário: um parecer do professor Orestes Guimarães, Inspetor Federal das Escolas Subvencionadas pela União, no Estado de Santa Catarina. Blumenau: Typografia Carl Wahle, 1929.

LUNA, José Marcelo Freitas de. O Português na escola alemã de Blumenau: da formação à extinção de uma prática - Ensinávamos e aprendíamos a Língua do Brasil. Itajaí: Ed. da UNIVALI; Blumenau; Ed. FURB, 2000.

NAGLE, Jorge. A educação na Primeira República. In: FAUSTO, Boris (Org.). História geral da civilização brasileira: o Brasil republicano. 7. ed. Rio de Janeiro: Bertrand Brasil, 2004. v. 2. t. III. p. 259-291.

OLIVEIRA, Lúcia Lippi; VELLOSO, Mônica Pimenta; GOMES, Ângela Maria de Castro (Org.). Estado Novo: ideologia poder. Rio Janeiro: Zahar Editores, 1982.

SANTOS, Ademir Valdir dos. Educação e nacionalismo: configurando a escola primária catarinense na Era Vargas. Revista Brasileira de História da Educação, v. 10, n. 3, p. 83-112, set./dez. 2010. Disponível em: <http://www.rbhe.sbhe.org.br/index.php/ rbhe/article/view/27>. Acesso em: 10 abr. 2016.

SANTOS, Ademir Valdir dos; MUELLER, Helena Isabel. Nacionalismo e cultura escolar no governo Vargas: faces da construção da brasilidade. Cadernos de História da Educação, v. 8, n. 2, p. 261-274, jan. 2010. Disponível em: <http://www.seer.ufu.br/ index.php/che/article/view/371 >. Acesso em: 10 abr. 2016.

SCHWARTZMAN, Simon; BOMENY, Helena Maria Bousquet; COSTA,Vanda Maria Ribeiro. Tempos de Capanema. São Paulo: Paz e Terra, 2000.

SOUZA, Rogério. A arte de disciplinar os sentidos o uso de retratos e imagens em tempos de nacionalização (1930-1945). Revista Brasileira de Educação, v. 19, n. 57, p 399-416, abr./jun. 2014.

TEIVE, Gladys Mary Ghizoni. A Escola Normal Catarinense sob a Batuta do Professor Orestes Guimarães. In: DALLABRIDA, Norberto (Org.). Mosaicos de Escolas: Modos de Educação em Santa Catarina e Primeira República. Florianópolis: Cidade Futura, 2003. p. 221-252.

TEIVE, Gladys Mary Ghizoni; DALLABRIDA, Norberto. A escola da República: os grupos escolares e a modernização do ensino 
primário em Santa Catarina (1911-1918). Campinas: Mercado de

Letras, 2011.

TOKARSKI, Fernando. Andar na aula: uma salvaguarda do polonismo. In: DALLABRIDA, Norberto (Org.). Mosaicos de Escolas: Modos de Educação em Santa Catarina e Primeira República. Florianópolis: Cidade Futura, 2003.

VARGAS, Getúlio. A nova política do Brasil: da Aliança Liberal às realizações do primeiro ano de governo (1930- 1931). Rio de Janeiro: José Olympio, 1938.

WEREBE, Maria José Garcia. Grandezas e misérias do ensino no Brasil. 2. ed. São Paulo: Ática, 1997.

Submetido em: 03/03/2016

Aprovado em: 29/08/2016

\title{
THE POLITICAL OF GETÚLIO VARGAS AND PRIMARY SCHOOLS SANTA CATARINA (1930-1945)
}

\begin{abstract}
This article discusses the Vargas politic and his group, as well as the nationalist project for schools of Santa Catarina between 1930 and 1945. The goal is to catch a dialogue resulting from efforts to understand the nationalist project Vargas in their characteristics, enables the understanding of the authoritarian character that had this project for primary schools in Santa Catarina, seeking to seize it in their moments of breaks before the spread of schools in southern Brazil. As for the methodology, will seek to make a general-apparatus of political reforms and educational policies that had as its government proponents, Education Minister Gustavo Capanema and the heads of the State of Santa Catarina. Among the reforms, it should be noted that the objective was to homogenize culture, disregarding existing in the state. In this sense, the fields of studies Campos (2008), Dallabrida (2001, 2003), that the key role that the school had those government projects was to make use of an arsenal of patriotic ideas, inspiration or even fascist fascist for the construction of a Brazilian identity as that "purê". It is part of the understanding that the government of Getulio Vargas period was marked by extreme nationalism, authoritarian, which penetrated the Santa Catarina schools. From the perspective of turning children into adults docile and obedient, in the symbolic field, the production of speeches in various sectors of that society brought form the so-called "national identity".
\end{abstract}

Keywords: Nationalist Politics. Authoritarism. Primary School Santa Catarina. 